\title{
Management Accounting Systems, Top Management Teams, and Sustainable Knowledge Acquisition: Effects on Performance
}

\author{
Andrés F. Ugalde Vásquez ${ }^{1, *}$ and David Naranjo-Gil ${ }^{2, *}$ \\ 1 Faculty of Administration Sciences/Vice-Rectorate for Research. Universidad del Azuay, Ave 24 de Mayo, \\ 7-77, y Hernán Malo, Cuenca 010107, Ecuador \\ 2 Financial Economics and Accounting Department, Universidad Pablo de Olavide, 41013 Seville, Spain \\ * Correspondence: augalde@uazuay.edu.ec (A.F.U.V.); dnargil@upo.es (D.N.-G.)
}

Received: 15 February 2020; Accepted: 5 March 2020; Published: 10 March 2020

\begin{abstract}
Organizations are increasingly aware of the importance of managing the acquisition processes of new and sustainable knowledge, which allows them to increase performance. These knowledge-acquisition processes require top management teams to focus on the external environment to search for sustainable opportunities and initiatives. This spurs top teams to make strategic decisions that require more comprehensive managerial information, which is provided by management accounting systems. Our research analyzes how top management team composition facilitates the acquisition of new knowledge. Our management accounting paper also analyzes the mediating effect of the interactive use of management accounting systems (MASs) and their impact on sustainable firm performance. A survey was conducted among the main manufacturer firms in the Republic of Ecuador. Results were analyzed by using the partial least squares methodology, and they showed a positive effect for the interactive use of management accounting systems on sustainable knowledge-acquisition processes. Results also showed that knowledge acquisition increased firm performance through an interactive use of MASs.
\end{abstract}

Keywords: knowledge acquisition; sustainability; top management team heterogeneity; interactive management accounting systems; firm performance

\section{Introduction}

Increasing public awareness on wellbeing has led organizations to recognize that manufacturing and industrial development is closely related to all facets of sustainability [1]. Furthermore, the modern economy has evolved from the industrial era toward a new information society, where the main assets of organizations are no longer their physical assets, and knowledge is becoming the most important factor of production [2]. Knowledge is a complex and elusive concept that has been defined in many ways [3]. It has been extensively defined as the use and retention of intangible resources of organizations [4]. The process of providing those resources, called knowledge provision, is classified in two dimensions [5]: where knowledge is developed inside the organization, which is called knowledge creation [6], and where knowledge is acquired from the environment, which is called knowledge acquisition [7]. Given the effects of industrial activities on the environment [1], sustainable development has drawn firms' attention, since they respond to changes in the global environment by focusing on acquiring sustainable knowledge [8].

Sustainability knowledge can be defined as the type of knowledge that improves the understanding, uptake, and end results of sustainability during project life cycles [1]. It usually comes in the form of experiences, guidelines, policies, and technology innovations, and how all of them have an impact 
on the environment [1]. Sustainability goals can only be achieved when stakeholders are informed of and continuously updated by the acquisition process of new knowledge toward sustainability in organizations, which allows constructing consensus and promoting specific measures for the pursuit of sustainability [1].

Recent research has focused on analyzing how organizations manage their knowledge [9] and has identified management accounting systems (MASs) as the key mediators to create sustainable value in the long term [10]. One of the main roles of MASs is to communicate [8], locate, and apply sustainability knowledge in organizations [11]. From this point of view, sustainability knowledge is based on a social communication process that can be improved though collaboration and co-operation tools [12]. The type of information provided by MASs determines the quality of decision-making [13]. Thus, an MAS could be understood not just as an information supplier tool, but as a system that provides top managers with updated, reliable, and accessible knowledge to facilitate decision-making [14]. Therefore, it is crucial to explore the way in which MASs are related to the acquisition of sustainability knowledge [15] and the role of top management teams during this process [16]. Our paper tries to cover this gap by analyzing how top managers use an MAS to improve a firm's performance and its relation with the acquisition process of new knowledge toward sustainability in organizations.

Our empirical study was conducted through a survey among the main manufacturer firms in the Republic of Ecuador. Data were analyzed by using the partial least squares methodology. Our results indicated the existence of a positive effect of the interactive use of management accounting systems on sustainable knowledge-acquisition processes, as well as a positive effect on a firm's performance. These findings allow top management teams (TMTs) to understand the value of knowledge-acquisition processes toward sustainability in organizations in a developing market where the topic is still unexplored. The rest of this paper is structured as follows: In Section 2, we develop our research hypothesis. In Section 3, we develop our empirical framework and research methodology. Finally, we discuss the findings and present the conclusions.

\section{Theoretical Background and Hypothesis Development}

There is broad agreement in the management literature about organizational knowledge affecting firm performance [17]. Knowledge can have a positive impact on several types of performance, including economic, environmental, and social [12]. Knowledge management (KM) has an integrated impact on the three perspectives of sustainability: economical, environmental, and social [12]. This implies a new approach to MASs as organizational knowledge repositories [18], as well as the role of TMTs in the creation of conditions to implement information and accounting systems [19] that link them to the acquisition of knowledge and the improvement of firm performance [20].

Upper-echelon theory [21] suggests the existence of a relation between TMT composition and firm performance [22], since TMTs better understand the organizational structure [23] and enable strategic change through decision-making [24]. In addition, sustainable management is achieved through multidisciplinary collaboration, which is highly dependent on the ability of TMTs to foster communication and interaction on all organizational levels [1]. One of the key factors is TMT heterogeneity (i.e., members' background and diversity of characteristics), which has a positive impact on team orientation toward innovation, diversification, and the search for new opportunities [25]. The bigger the set of cognitive resources is, the wider the range of strategic perspectives that a heterogeneous top team can share [25].

The acquisition of knowledge is part of the search for opportunities by a TMT, given its capacity to question the organizational assumptions [26]. This acquired knowledge, external by definition, is less susceptible to influence by traditional firm archetypes established in the organizational memory [27]. Acquired knowledge is also influenced by the context and cognitive state of team members inside the firm [26], which usually generates a certain level of environmental uncertainty until the team acquires some familiarity to it [28]. From this point of view, the TMT's role is crucial [22] because top teams allow the transfer of knowledge-acquisition outcomes to the rest of 
the firm [29]. Furthermore, they allow the transformation of knowledge into tangible outcomes such as organizational strategies [30]. These decisions have important long-term consequences on organizational performance [31], since sustainability can only be accomplished when organizations acquire new knowledge and transfer it across the organizational and hierarchical levels. Thus, it is key for organizations to not only build but also manage sustainability knowledge [30].

The acquisition of knowledge also influences the TMT cognitive base, since knowledge-acquisition frequency influences the TMT's heterogeneity level (e.g., new members in the TMT). Therefore, the greater the amount of knowledge acquired by the TMT is, the greater the chance of achieving sustainable solutions, which helps to monitor the environment and acquire relevant knowledge [32]. This is the reason why upper-echelon theory needs a new angle that focuses on the mechanisms through which the TMT explores, analyzes, and communicates management information [21]. Hence, a direct relationship can be expected between TMT heterogeneity and knowledge-acquisition processes, since heterogeneous TMTs are able to conduct this knowledge-acquisition process with greater richness. Therefore, we formulated the following research hypothesis:

Hypothesis 1 (H1). Top management team heterogeneity is positively related to the acquisition process of new knowledge toward sustainability in organizations.

Management accounting systems (MASs) are defined as systematic processes of control used to influence members in organizations to achieve the firm's goals [33]. Two styles of MAS use can be identified: diagnostic use, which is financially and historically oriented, and interactive use, which is non-financially, prospectively, and technologically oriented [33]. As markets have become more globalized, firms have developed MASs that seek to identify information for consolidating organizational strategies and for assigning meaning, content, and context to them [34]. These new MASs are traditional ones, which were designed to store great amounts of organizational information [35]. The knowledge management is defined as the capacity of strengthening the firm competitiveness through the creation of value from the organization's intangible resources [36]. Hence, the competitiveness will depend on how the knowledge is acquired, controlled, and integrated into the firm [37]. In addition, the importance of promoting sustainability through knowledge management enables the capacity to communicate decisions, achieve consensus, and promote specific measures [1].

Currently, an increasing number of firms are aware of the potential of sustainability knowledge to promote innovations and cultural changes in organizations [12]. Interactive MAS use allows the acquisition of knowledge [38] in two different ways: firstly, by connecting people and allowing learning networks and secondly, by allowing knowledge storage and codification [39]. Management research has extensively focused on the influence of knowledge management in MAS development [14], allowing it to generate more reliable and strategic information [13]. This implies understanding MASs from a more dynamic perspective, which is oriented toward best practices [40], organization culture, and better understanding of the firm's environment [41]. As information technologies evolved, more complex tools were also developed [13], not only at top management levels (e.g., balanced scorecards) but also at operative process levels (e.g., enterprise resource planning (ERP)) [14]. Finally, sustainability goals also need well-informed and continuously updated customers and stakeholders, which occur through specific MASs [1]. Thus, research has focused on knowledge-evolving processes from their tacit form (e.g., related to identity, social exchange, and learning) to MASs as explicit knowledge repositories (e.g., related to documents that are captured and processed through an organization's information technologies) [42].

To promote sustainability and deliver tangible results, it is necessary to adopt sustainability principles during business planning and operation [1]. It is not just about the MAS as a technology system, but also about an integrated model [43] that allows knowledge to become part of the organizational routines and keeps organizational learning processes active [44]. Knowledge storage in an MAS represents the mechanism used to institutionalize knowledge for future usage [18]. Therefore, 
firms can be understood as communities differentiated by their ability to acquire, create, integrate, and transfer knowledge [16]. This ability is more effective to the extent that MASs are applied through an interactive use style [4]. Some research has examined interactive MAS use as a mediator between innovation and effectiveness [4]. On this topic, the upper-echelon literature emphasizes that organizational innovation could be understood from TMT characteristics [33]. Indeed, TMT composition shapes organizational behavior, given that its cognitive configuration guides its method to search and filter information provided by MASs [33]. TMTs that interactively use MASs are able to better facilitate strategic change in organizations [33], since the interactive use of MASs provides TMTs with a more comprehensive perspective that includes multiple types of information (e.g., financial and nonfinancial, internal and external) [45]. This is the reason why firms should use their MAS to understand their managerial skills on the basis of knowledge acquisition and its later internal applications [46]. Interactive MAS use allows the integration of knowledge into the firm's core competences [47] and makes knowledge not just a TMT's tool but also a mechanism that allows adaptation to to environmental change, generates opportunities, increases information flow, improves innovation, and enhances technology transfer [48].

The interactive use of an MAS implies dialogue and communication between TMT members with the purpose of identifying opportunities and new resources [4]. The upper-echelon literature suggests that this dialogue is more likely to occur between heterogeneous TMTs given their higher mental amplitude, opportunities, and innovation orientation, which can also be explained by the larger pool of cognitive resources that heterogeneous TMTs share on the basis of their more multifaceted experiences and backgrounds [25]. Moreover, heterogeneous TMTs are likely to use MASs in a horizontal rather than hierarchical way, such as an instrument to encourage control and co-ordination as constitutive elements of interactive use [33]. This occurs since MAS construction as a knowledge enabler was recognized as a capable strategy to respond to a firm's requirements in order to improve its core competences [43]. This is helpful to organizations in which the business logic confronts them with vast amounts of information that needs to be organized and spread [46]. The literature suggests that interactive MAS use is linked to innovation, knowledge, and performance [4]. In the same way, the interactive use of MASs has been identified as an important mediator in the relationship between TMTs and strategic change [33]. Therefore, it can be expected that interactive use of MASs accomplishes a mediator function between TMTs and knowledge acquisition. Thus, we formulated the following hypothesis:

Hypothesis 2 (H2). Interactive use of management accounting systems has a positive mediator effect between heterogeneous top management teams and the acquisition process of new knowledge toward sustainability in organizations.

The literature suggests the existence of a relationship between knowledge acquisition and firm performance [49], which is based on previously well-known direct relationships with multiple variables related to organizational effectiveness [50]. Some of these variables are strategic renovation, time reduction, outsourcing process success, work team performance, and organizational capabilities [51] and sustainability development [1]. Therefore, it is not difficult to build a logical link between sustainability and business development, while enterprises feel pressure to focus on their environmental impact and not just on their economic growth [8]. Some research proposes to understand performance as a consequence of TMT sustainable knowledge acquisition [52]. However, although firms dedicate resources to knowledge acquisition, they do not dedicate the same effort to measure their outcomes. Thus, tangible benefit identification becomes difficult [18]. There is still little evidence of knowledge management's influence on performance, especially in emergent economies where it is still a new research matter [18]. Therefore, we formulated the following hypothesis:

Hypothesis 3 (H3). Knowledge-acquisition processes toward sustainability in organizations are positively related to firm performance. 
Our hypotheses are summarized in the research model shown in Figure 1.

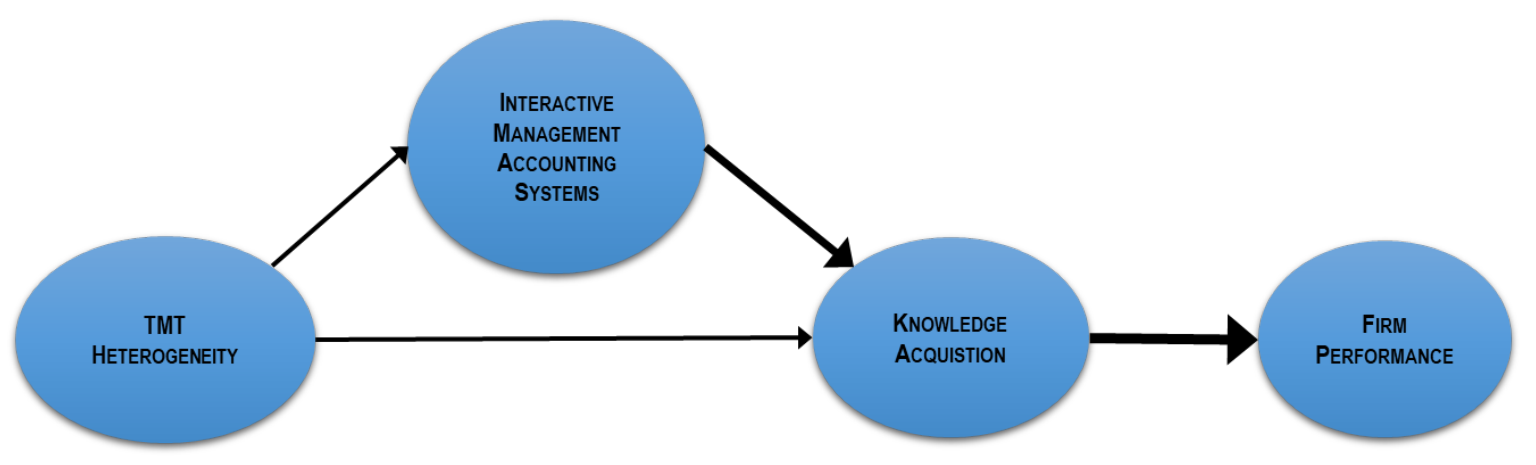

Figure 1. Research model.

\section{Materials and Methods}

Our empirical data were obtained from leading clusters of the private manufacturing sector in the south of the Republic of Ecuador [53]. This setting fit well with our research objectives, since Ecuador is promoting the transformation of its productive matrix, which requires significant levels of innovation for the industrialization process [53]. Southern Ecuador especially has high dynamic industrial activity, with the only city in the country in which manufacturing activity is bigger than commercial activity [54]. This allowed us to work on a sector that has dynamism, innovation, and shows clear similarities with other economies in emerging regions and countries, which facilitated the generalization of the obtained results. Our study covered the most important industrial area, which contains $70.77 \%$ of the large manufacturing companies of the country. We focused on the main firms of the private manufacturing sector, since they have greater management capacity to analyze knowledge-management processes [55], which requires more complex management structures and much higher investments [5]. Furthermore, firms in this sector have similar market structures, which reduces multiple-sample bias and increases control over environment variability [56]. The included clusters and their participation are shown in Figure 2.

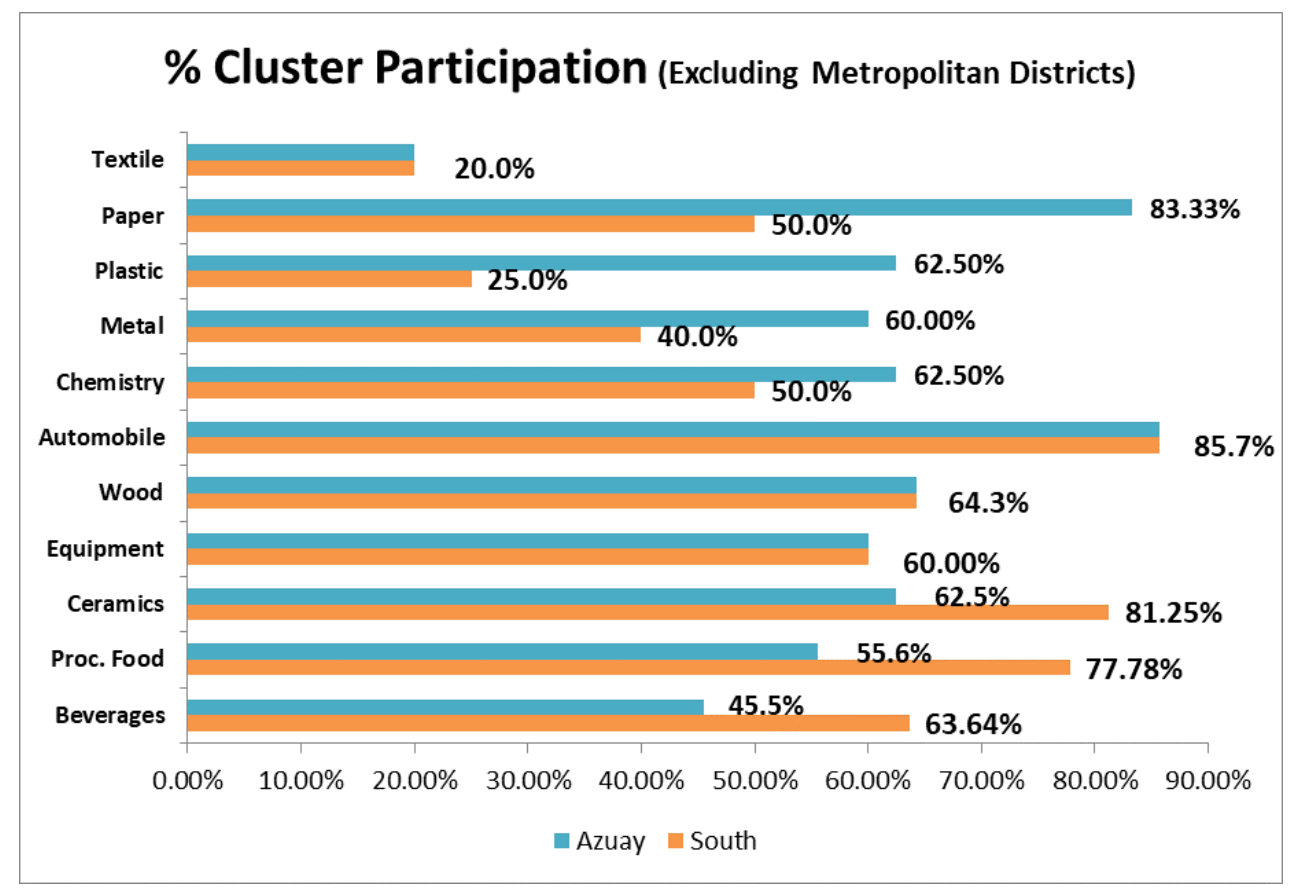

Figure 2. Cluster participation. Source: Special Taxpayer Registry (SRI, 2017). 
The methodological process started with analysis of the Internal Revenue Service database (Servicio de Rentas Internas del Ecuador (SRI), 2012) and the Special Taxpayer database [57]. This information was filtered according to firms' tax status to only include active firms; "special taxpayer" status (e.g., large companies with high transaction volume); legal status (e.g., only companies or corporations) of being legally required to keep accounting registers; and, finally, according to main business offices to avoid redundant information that could provide branch offices [58]. The filtered database was complemented by an exploratory study through the Internet and telephone calls. The outcome was a database of 89 firms. Later, 27 firms were discarded due to different reasons, such as not being part of the manufacturing sector or having small organizational structures and TMTs.

We contacted the firms following a standard TMT model that included not only the CEO but also vice managers, such as those of human management, financial, production, and commercial units [59]. A total of 310 questionnaires were distributed in 62 firms following Dillman's procedure [60], which increases the possibility of avoiding typical errors associated with survey research. Before questionnaire development, 12 interviews were conducted with different TMT members in the manufacturing sector in order to establish a previous parameter about to what KM and MAS diffusion refers. Interviews showed that TMT members had an overall knowledge about their fields and techniques. This preliminary version was reviewed by an expert, whose suggestions were used to improve ambiguous items and inaccurate measurement scales. This reviewed questionnaire was applied in a pilot study with 31 managers from the study sample. The outcomes of the pilot study were used to improve survey features on writing and questionnaire length. With an overall sample of 50 firms and 207 complete questionnaires, we achieved an $83 \%$ rate of satisfactory responses, which allowed us to gather the information of 21 full TMTs (five members), 15 TMTs with four members, and 14 TMTs with three members (minimum required). Since the survey was filled out on an online system, the software did not allow partial or incomplete questionnaires; consequently, all received surveys were included on the study.

\section{Variable Measurement}

All variables were adapted from already validated scales used in the management literature, which were measured with a five-point Likert scale in order to preserve online survey homogeneity. Firm performance and effectiveness were measured by asking managers about how the organization improved over the past two years in terms of different aspects such as innovation in new products or services, identification of new business opportunities, co-ordination of efforts in different units, commercialization of new innovations, and adaptation to unanticipated changes or crises.

We used the Gold scale for measuring knowledge-acquisition processes toward sustainability [61]. Since this scale uses 12 items for measuring both internal and external knowledge acquisition, we ran factorial analysis that showed four items loaded on internal knowledge acquisition and eight items loaded on external knowledge acquisition (see Table A1). Only these eight items were used for measuring the knowledge-acquisition process toward sustainability. Items were modeled to be reflective and manifested indicators of the constructs, where every TMT was asked to rate each factor on a scale from 1 (very low) to 5 (very high). Each variable was processed to obtain the TMT average for each indicator.

TMT heterogeneity was measured according to Naranjo-Gil and Hartmann [25] and NaranjoGil [62] by using TMT characteristics such as tenure, age, education, experience, and formation. Tenure was measured by four items rated on a scale from 1 (five years or less) to 5 (20 years or more). Age was measured by one item on a scale from 1 (30 years or less) to 5 (60 years or more). Education and formation were composed of one and two items, respectively, modelled as formative indicators and measured on a scale from 1 (none) to 5 (Master's or Ph.D.). Tenure, age, and education were processed by calculating the variation coefficients for each TMT. Formation and experience were treated by calculating the Blau index for each variable and TMT [59]. We standardized the scores of all variables to measure TMT heterogeneity. 
MAS use was measured using an ordinal scale to capture differences in the extent of the use of the techniques [63]. The interactive use of an MAS was measured through a scale composed of five items, from 1 (very rare) to 5 (total) [25]. Respondents were asked to indicate the extent to which they used an MAS for different managerial decisions, such as for negotiating objectives and targets, for encouraging new goals and priorities, for signaling key strategic areas, and for involving subordinates in face-to-face interaction and debate. Factorial analysis revealed that all items were loaded on one factor, which was interactive MAS use. Subsequently, we calculated the average of every indicator within each TMT. The control variables of our study were the firm's size, measured by the number of employees, and the position occupied by the respondent TMT member [63]. Appendix B shows the items used for each research variable.

\section{Analysis and Results}

We analyzed our data by using the partial least squares (PLS) technique, a method based on minimizing residual variances of dependent variables. Similar to structural equation modeling based on covariance (LISREL or EQS), PLS methodology focuses on variance prediction in dependent variables, and it allows working with smaller samples than those used in covariance-based models [64]. Path coefficients are equivalent to the $\beta$ (beta) statistical components of minimum square ordinary regression [64]. Furthermore, PLS allows working simultaneously with the measurement model and the internal structural relations without making assumptions about the data distribution pattern [65]. The PLS prediction model explains how each item is related to its construct or latent variable in terms of convergent validity, discriminant validity, and reliability [65]. Our analysis confirmed that every coefficient exceeded the required minimal levels. Average variance extracted (AVE), which seeks to measure the amount of variance captured by a latent variable on the amount caused by the measurement error, was greater than 0.50 in all our constructs. This means that interactive MAS use, knowledge acquisition, and firm performance, as latent variables, could explain the model's behavior (variation) to a greater extent than measurement error does. Cronbach's alpha and composite reliability coefficients were greater than 0.80 , which means that the chosen scales to measure each construct were reliable and consistent. Overall, the coefficients showed an adequate level of adjustment; results are shown in Table 1.

Table 1. Construct reliability and validity. MAS, management accounting system.

\begin{tabular}{cccc}
\hline \multicolumn{3}{c}{ Construct Reliability and Validity } \\
\hline & Cronbach's Alpha & Composite Reliability & $\begin{array}{c}\text { Average Variance } \\
\text { Extracted (AVE) }\end{array}$ \\
\hline Firm Performance & 0.898 & 0.918 & 0.556 \\
Knowledge Acquisition & 0.874 & 0.902 & 0.539 \\
Interactive MAS Use & 0.882 & 0.909 & 0.627 \\
\hline
\end{tabular}

The model's discriminant validity was evaluated by calculating average variance extracted (AVE) and comparing it with the correlations between constructs, which showed a satisfactory level (above 0.7). We could conclude that the chosen variables to explain interactive MAS use, knowledge acquisition and performance, were mostly correlated with their own constructs. Likewise, analysis of general cross loadings of manifest variables in latent variables also fulfilled the required parameter in all construct items. Details of the discriminant validity analysis are shown in Table 2. 
Table 2. Discriminant validity.

\begin{tabular}{cccc}
\hline \multicolumn{3}{c}{ Discriminant Validity } \\
\hline \multicolumn{4}{c}{ Fornell-Larcker Criterion } \\
\hline & Knowledge Acquisition & Firm Performance & Interactive MAS Use \\
\hline Knowledge Acquisition & 0.734 & & \\
Firm Performance & 0.752 & 0.746 & 0.792 \\
Interactive MAS Use & 0.689 & 0.712 & \\
\hline
\end{tabular}

We also examined the model for multicollinearity problems. Collinearity increases standard errors, and the common rule is that there is multicollinearity when the variance inflation factor (VIF) is greater than 4.0. In this case, the model did not show any problems of multicollinearity in its indicators or its constructs. A bootstrapping process with 5000 samples with random replacement was conducted to estimate the significance of the beta (path) coefficients in the model. As shown in Figure 3, a TMT is not significantly related to the knowledge-acquisition process, which does not confirm our first hypothesis. Furthermore, the mediating effect of interactive MAS use between TMT heterogeneity and the knowledge-acquisition process was not supported (Hypothesis 2). However, we could observe a clear and significant relationship between interactive MAS use and knowledge acquisition (0.619). Finally, knowledge-acquisition processes were positively and significantly related to firm performance (0.761), which supported Hypothesis 3. The research model explained $56.5 \%$ (factor $\mathrm{r} 2$ ) of variance in firm performance and $54.6 \%$ of the knowledge-acquisition processes, which indicated that our measures captured a large part of variable behavior. Overall, our model showed high predictive power (see Figure 3 below).

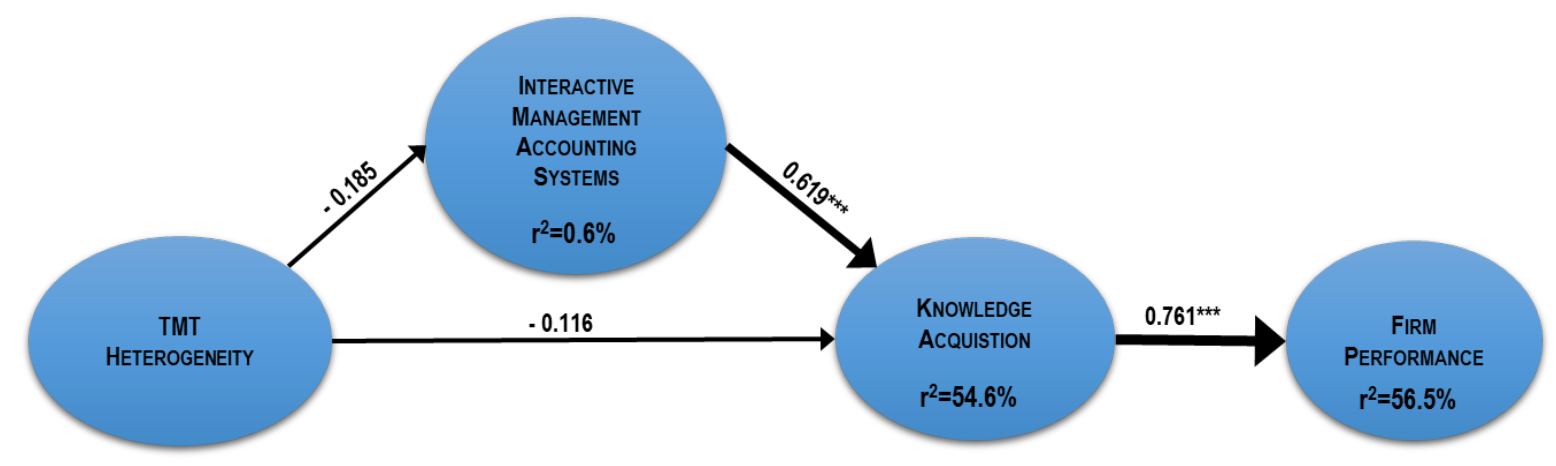

Figure 3. Partial least squares (PLS) model.

Once correlation factors were determined (factor $\mathrm{r} 2$ ), we analyzed to what extent these factors varied through F-square distribution (factor $\mathrm{f} 2$ ). This is continuous probability distribution in which, according to accepted standards, a value above 0.15 represents an average effect, and a value above 0.35 represents a high effect (See Table 3). In $\mathrm{f} 2$ values, all relations between latent variables of the constructs exceeded the optimal indicator, except for TMT heterogeneity-interactive MAS use. This suggests that knowledge acquisition explains firm performance variation over any other used variable in the model. Likewise, the interactive use of an MAS explains variance in knowledge acquisition over all other used variables. We also analyzed the outer loadings of the model to represent the standard weights of the factors toward their constructs. These external loads represent the contribution of an indicator in the definition of the latent variable, which must exceed the value of 0.70 . It is also recommended that if the indicator load is below 0.40 , it should be withdrawn in order to improve composite reliability. Most indicators exceeded 0.70, and none of them was below 0.40 . 
Table 3. F-square. TMT, top management team.

\begin{tabular}{cccc}
\hline \multicolumn{3}{c}{ F-Square } \\
\hline & Firm Performance & Knowledge Acquisition & Interactive MAS Use \\
\hline $\begin{array}{c}\text { TMT Heterogeneity } \\
\text { Knowledge Acquisition } \\
\text { Interactive MAS Use }\end{array}$ & 1.299 & 0.158 & 0.063 \\
\hline
\end{tabular}

The results of our study showed that a significant proportion of a firm's performance can be explained through knowledge acquisition. In other words, our results showed a direct and positive influence of knowledge acquisition on a firm's performance. These results also suggest that knowledge acquisition is positively related to sustainability in organizations, given that knowledge acquisition is strongly related to sustainability as a part of effectiveness [1]. This is consistent with previous findings in the management literature, where other processes related to knowledge management (i.e., transfer, creation, integration, and infrastructure) have been related to effectiveness, innovation, and sustainability.

\section{Discussion and Conclusions}

The objective of this paper was to explore the relationship between top management teams and the acquisition of sustainability knowledge using management accounting systems. In addition, we analyzed their effect on firm performance.

Our findings showed a clear relationship between interactive MAS use and knowledge acquisition. They also showed that a very important part of knowledge acquisition is explained by interactive MAS use. This means that processes by which organizations acquire knowledge improve when top managers interactively use an MAS. Therefore, MAS development that prioritizes prospective, sustainable, and nonfinancial information facilitates managers to enhance knowledge-acquisition processes. These results have important consequences for organizations, since they show that it is key to use MASs appropriately to enhance knowledge acquisition. An interactive use of an MAS encourages organizational learning and knowledge acquisition. Thus, managers should use management information and accounting systems to involve themselves regularly and personally in the decision activities of subordinates, which facilitates a continuous interaction and exchange of information between organizational members. This is consistent with findings in the management literature regarding the construction of knowledge management systems [4], of which the purpose is to increase meaning in a firm's information as a tool to support their top management teams' decision-making.

Our findings showed that management accounting systems do not have a mediating effect between top management teams and knowledge acquisition. This could be because knowledge-acquisition processes could be delegated to middle or operative management teams. Future research should therefore analyze the use of MASs by middle managers for decision-making and knowledge-acquisition processes.

Our study also established a positive and significant relationship between knowledge-acquisition processes and firm performance, which builds a link between knowledge acquisition and business development [15]. Our findings allowed us to understand better performance as a result of sustainable knowledge acquisition and thus examine performance related to environmental impact and not just related to economic growth. Thus, results from this study let us to conclude that organizations must become more aware of the value of knowledge-acquisition processes toward sustainability, which directly affects firm performance, both economic and social. Our results showed evidence of the key role of interactive MAS use and its relationship with different knowledge management processes. Furthermore, this paper is one of the first to focus on studying the use and behavior of these variables in an emerging economy. Therefore, our findings contributed to better understanding the value of knowledge management in emerging markets. Higher performance and competitive edge can be 
boosted in organizations by acquiring knowledge in their field of operation. The knowledge acquisition process can be used to gain a competitive advantage, by scanning and monitoring new knowledge from the environment and competitors. Our research shows evidence that knowledge acquisition lets organizations identify opportunities for attracting customers and opening new opportunities, which consequently enhance firm performance.

Our paper also has some limitations. Our questionnaire gathered information on knowledge-acquisition processes both directly (from an external source) and through the way these processes are integrated into an organization, which may generate confusion. Furthermore, our results were based on a study carried out at the TMT level on companies in the manufacturing sector in Ecuador. Our empirical setting was adequate, but it could contain idiosyncrasies of the manufacturing industry. Thus, future research could extend our results in three directions: First, future studies could focus not only on top management teams but also on middle hierarchical teams and even operative teams. Second, future studies could also analyze nonmanufacturing industries more related to trade or services. Third, future research could extend our study to a broader sample of companies in an international context.

Author Contributions: The manuscript was written through join contributions from the two authors. The authors participated in developing the article and the methodology, and writing the paper. In this study A.F.U.V. obtained the data-source from Ecuador and D.N.-G. revised the final version of the paper. The two authors have given approval to the final version of the manuscript. All authors have read and agreed to the published version of the manuscript.

Funding: This research was supported by the Spanish Ministry of Science, Innovation and Universities (PGC2018-094989-B-I00).

Acknowledgments: We would like to thank and acknowledge the firms and enterprises who filled out the questionnaires and the universities that sponsored this study.

Conflicts of Interest: The authors declare no conflict of interest.

\section{Appendix A}

Table A1. Factorial analysis (rotated component matrix).

\begin{tabular}{|c|c|c|c|}
\hline \multirow{2}{*}{ Items } & & \multicolumn{2}{|c|}{ Knowledge Acquisition } \\
\hline & & External & Internal \\
\hline 1 & My organization has processes for acquiring knowledge about our customers. & 0.654 & 0.329 \\
\hline 2 & $\begin{array}{l}\text { My organization has processes for generating new knowledge from existing } \\
\text { knowledge. }\end{array}$ & 0.682 & 0.338 \\
\hline 3 & My organization has processes for acquiring knowledge about our suppliers. & 0.210 & 0.574 \\
\hline 4 & My organization uses feedback from projects to improve subsequent projects. & 0.545 & 0.475 \\
\hline 5 & $\begin{array}{l}\text { My organization has processes for distribution knowledge throughout the } \\
\text { organization. }\end{array}$ & 0.603 & 0.564 \\
\hline 6 & $\begin{array}{l}\text { My organization has processes for exchanging knowledge with our business } \\
\text { partners. }\end{array}$ & 0.406 & 0.788 \\
\hline 7 & My organization has processes for interorganizational collaboration. & 0.190 & 0.783 \\
\hline 8 & $\begin{array}{l}\text { My organization has processes for acquiring knowledge about new } \\
\text { products/services within our industry. }\end{array}$ & 0.880 & 0.242 \\
\hline 9 & $\begin{array}{l}\text { My organization has processes for acquiring knowledge about competitors } \\
\text { within our industry. }\end{array}$ & 0.790 & 0.267 \\
\hline 10 & My organization has processes for benchmarking performance. & 0.828 & 0.142 \\
\hline 11 & My organization has teams devoted to identifying best practices. & 0.472 & 0.469 \\
\hline 12 & My organization has processes for exchanging knowledge between individuals. & 0.195 & 0.804 \\
\hline
\end{tabular}

Note: Items in bold were used to measure knowledge acquisition (items 1, 2, 4, 5, 8, 9, 10, and 11). 


\section{Appendix B Items for Each Research Variable}

\section{TMT Heterogeneity}

- Age

- University degree and title (years of education in medicine or general management/law)

- Years of experience as a clinician/doctor at public hospitals

- Years of experience as a clinician/doctor at other health care organizations

- Years of experience as a manager in current hospital

- Years of experience as a manager in other health care organizations

\section{Interactive use of MAS}

- Set and negotiate goals and targets

- Debate data assumptions and actions plans

- Challenge new ideas and ways of doing tasks

- Involvement in a permanent discussion with subordinates

- Learning tool

Firm Performance

Over the past two years, my organization has improved its ability to ...

- Innovate new products/services.

- Identify new business opportunities

- Coordinate the development efforts of different units.

- Anticipate potential market opportunities for new products/services.

- Rapidly commercialize new innovations.

- Adapt quickly to unanticipated changes.

- Anticipate surprises and crises.

- Quickly adapt its goals and objectives to industry/market changes.

- Decrease market response times.

- React to new information about the industry or market.

- Be responsive to new market demands.

- Avoid overlapping development of corporate initiatives.

- Streamline its internal processes.

- Reduce redundancy of information and knowledge.

\section{References}

1. Yang, J.; Yuan, M.; Yigitcanlar, T.; Newman, P.; Schultmann, F. Managing knowledge to promote sustainability in Australian transport infrastructure projects. Sustainability 2015, 7, 8132-8150. [CrossRef]

2. Rašula, J.; Vukšić, V.B.; Štemberger, M.I. The impact of knowledge management on organizational performance. Econ. Bus. Rev. 2012, 14, 147-168.

3. Nonaka, I.; Takeuchi, H. The Knowledge-Creating Company. How Japanese Companies Create the Dynamics of Innovation; Oxford University Press: New York, NY, USA, 1995.

4. Lu, C.; Zhu, D.; Chang, Y. The moderating role of the interactive use of Management Accounting Systems (MCS) on the relation between knowledge management types and marketing project performance. Afr. J. Bus. Manag. 2001, 5, 687-698.

5. El Sawy, O.A.; Malhotra, A.; Gosain, S.; Young, K. IT-enebled value innovation in the electronic economy: Insight from marshal industry. MIS Q. 2000, 23, 305-335. [CrossRef]

6. Bousa, R.; Venkitachalam, K. Aligning strategies and processes in knowledge management: A framework. J. Knowl. Manag. 2013, 17, 331-346. [CrossRef] 
7. Pinho, I.; Rego, A.; Cunha, M.P. Improving knowledge management processes: A hybrid positive approach. J. Knowl. Manag. 2012, 16, 215-242. [CrossRef]

8. Van Der Meer, R.; Sinnappan, S. The role of knowledge management in an organization's sustainable development. In Proceedings of the Knowledge Management International Conference, Langkawi, Malaysia, 10-12 June 2008; University of Wollongong: Bega, Australia, 2008; pp. 1-6.

9. Huang, L.-S.; Lai, C.-P. An investigation on critical success factors for knowledge management using structural equation modelling. Technol. Manag. 2012, 40, 24-30.

10. Obeidat, B.Y.; Masa'deh, R.; Abdallah, A.B. The relationships among human resource management practices, organizational commitment, and knowledge management processes: A structural equation modeling approach. Int. J. Bus. Manag. 2014, 9, 9-26. [CrossRef]

11. Ditillo, A. Designing management accounting systems to foster knowledge transfer in knowledge-intensive firms: A network-based approach. Eur. Account. Rev. 2012, 21, 425-450.

12. Centobelli, P.; Cerchione, R.; Esposito, E. Knowledge management in startups: Systematic literature review and future research agenda. Sustainability 2017, 9, 361. [CrossRef]

13. Ferreira, A.A.; Kuniyoshi, M.S. Critical factors in the implementation process of integrated management systems. J. Inf. Syst. Technol. Manag. 2015, 12, 145-164. [CrossRef]

14. Azevedo, P.S.; Romão, M.; Rebelo, E. Success factors for using ERP (Enterprise Resource Planning) systems to improve competitiveness in the hospitality industry. Tour. Manag. Stud. 2014, 10, 165-168.

15. Sureena, M.; Mahmood, A.K. The review of approaches to knowledge management system studies. J. Knowl. Manag. 2013, 17, 472-490.

16. Green, G.; Liu, L.; Qi, B. Knowledge based management information systems for the effective business performance of SME's. J. Int. Technol. Inf. Manag. 2009, 18, 201-222.

17. Spender, J.C.; Grant, R.M. Knowledge and the firm: Overview. Strateg. Manag. J. 1996, 17, 5-9. [CrossRef]

18. Shehata, G.M. Leveraging organizational performance via knowledge management systems platforms in emerging economies: Evidence from the Egyptian Information and Communication Technology (ICT) industry. J. Knowl. Manag. Syst. 2015, 45, 239-278. [CrossRef]

19. Simons, T.; Peterson, R.S. Task conflict and relationship conflict in top management teams: The pivotal role of intra group trust. Adm. Sci. Q. 2000, 85, 102-111. [CrossRef] [PubMed]

20. Moilanen, S. Knowledge translation in management accounting and control: A case study of a multinational firm in transitional economies. Eur. Account. Rev. 2007, 16, 757-789. [CrossRef]

21. Hambrick, D.; Mason, P. Upper echelons: The organization as a reflection of its top managers. Acad. Manag. Rev. 1986, 9, 193-206. [CrossRef]

22. Certo, T.S.; Lester, R.H.; Dalton, C.M.; Dalton, D.R. Top management teams, strategy and financial performance: A meta-analytical examination. J. Manag. Stud. 2006, 43, 813-839. [CrossRef]

23. Teece, D.J.; Pisano, G.; Schuen, A. Dynamic capabilities in strategic management. Strateg. Manag. J. 1997, 18, 509-534. [CrossRef]

24. Naranjo-Gil, D. The role of top management teams in hospitals facing strategic change: Effects on performance. Int. J. Healthc. Manag. 2015, 8, 34-41. [CrossRef]

25. Naranjo-Gil, D.; Hartman, F. Management accounting systems, top management team heterogeneity and strategic change. Account. Organ. Soc. 2007, 32, 735-756. [CrossRef]

26. Pein, R.; Maier, R. SimKnowledge-Analyzing impact of knowledge management measures on team organizations with multi agent-based simulation. Inf. Syst. Front. 2011, 13, 621-636. [CrossRef]

27. Crossan, M.M.; Berdrow, I. Organizational learning and strategic renewal. Strateg. Manag. J. 2003, 24, 1087-1105. [CrossRef]

28. Katila, R.; Ahuja, G. Something old, something new: A longitudinal study of search behavior and new product introduction. Acad. Manag. J. 2002, 45, 1183-1194.

29. Tomé, E.; Figueiredo, P. Knowledge management and politics at the highest level: An exploratory analysis. Manag. Dyn. Knowl. Econ. 2015, 3, 193-212.

30. Akbari, A.; Reza, M. The study of the effects of knowledge management on innovation and organizational performance: Case study in small and medium enterprises in Qom. Eur. Online J. Nat. Soc. Sci. 2015, 4, 677-686.

31. Micic, R. Leadership role in certain phases of knowledge management processes. Ekonomika 2015, 61, 47-56. [CrossRef] 
32. Cooke, N.; Salas, E.; Cannon-Bowers, J.A.; Stout, R. Measuring team knowledge. Hum. Factors 2000, 42, 151-179. [CrossRef]

33. Naranjo-Gil, D.; Hartmann, F. How top management teams use management accounting systems to implement strategy. J. Manag. Account. Res. 2006, 18, 21-53. [CrossRef]

34. Malmi, T.; Brown, D.A. Management accounting systems as a package-Opportunities, challenges and research directions. Manag. Account. Res. 2008, 19, 287-300. [CrossRef]

35. Sajeva, S. The analysis of key elements of socio-technical knowledge management system. Econ. Manag. 2010, 15, 765-774.

36. Nonaka, I. A dynamic theory of organizational knowledge creation. Organ. Sci. 1994, 5, 14-37. [CrossRef]

37. Girish, G.P.; Joseph, D.; Amar Rajú, G. Factors influencing adoption of knowledge management systems in India from a micro, small and medium enterprise's perspective. Int. Rev. Manag. Market. 2015, 5, 135-140.

38. Hung, S.; Tang, K. Expanding group support system capabilities from the knowledge management perspective. J. Int. Technol. Inf. Manag. 2006, 17, 21-42.

39. Rao, Y.; Guo, K.; Chen, Y. Information systems maturity, knowledge sharing, and firm performance. Int. J. Account. Inf. Manag. 2015, 23, 106-127. [CrossRef]

40. Deokar, V.A.; El-Gayar, F.O.; Samikar, S.; Wills, J.M. Communications of the association for information systems. Commun. AIS 2010, 20, 565-598.

41. Frigotto, M.L.; Coller, G.; Collini, P. The strategy and management accounting systems relationship as emerging dynamic process. J. Manag. Gov. 2013, 17, 631-656. [CrossRef]

42. Grant, R.M. Toward a knowledge-based theory of the firm. Strateg. Manag. J. 1996, 17, 109-122. [CrossRef]

43. Rosca, V. A model for eliciting expert knowledge into sports-specific knowledge management systems. Rev. Int. Comp. Manag. 2014, 15, 57-68.

44. Kruger, C.J.; Johnson, R.D. Information management as an enabler of knowledge management maturity: A South African perspective. Int. J. Inf. Manag. 2010, 30, 57-67. [CrossRef]

45. Kaplan, R.S.; Norton, D.P. The Balanced Scorecard: Translating Strategy into Action; Harvard Business School Press: Boston, MA, USA, 2004.

46. Năstase, M.; Predişcan, M.; Roiban, R.N. The role of employees in a process of change-A case study for the romanian organizations. Rev. Int. Comp. Manag. 2013, 14, 512-518.

47. Herremans, I.M.; Isaac, R.G.; Kline, T.J.B.; Nazari, J.A. Intellectual capital and uncertainty of knowledge: Control by design of the management system. J. Bus. Eth. 2011, 98, 627-640. [CrossRef]

48. Kasper, H.; Mühlbacher, J.; Müller, B. Intra-organizational knowledge sharing in MNCs depending on the degree of decentralization and communities of practice. J. Glob. Bus. Technol. 2008, 4, 59-67.

49. Lane, P.J.; Koka, B.R.; Pathak, S. The reification of absorptive Capacity: A critical review and rejuvenation of the construct. Acad. Manag. Rev. 2006, 31, 833-863. [CrossRef]

50. Yao-Sheng, L. The effect of human resource Management Accounting Systems on the relationship between knowledge management strategy and firm performance. Int. J. Manpow. 2011, 32, 494-511.

51. Zahra, S.A.; George, G. Absorptive capacity: A review, reconceptualization, and extension. Acad. Manag. Rev. 2002, 27, 185-203. [CrossRef]

52. Yuan, X.; Guo, Z.; Fang, E. An examination of how and when the top management team matters for firm innovativeness: The effects of TMT functional backgrounds. Innov. Manag. Policy Pract. 2014, 16, 323-342. [CrossRef]

53. National Secretary of Planning and Development-SENPLADES. Official Registry No. 290. 12 May 2012. Presidency of the Republic. Available online: https://www.planificacion.gob.ec/wp-content/uploads/ downloads/2013/12/Buen-Vivir-ingles-web-final-completo.pdf (accessed on 29 June 2018).

54. Jácome, H.; King, K. Estudios Industriales de la Micro, Pequeña y Mediana Empresa. FLACSO-MIPRO 2012, 1, 45-80, 175-244.

55. Barreneche García, A.; Bounfour, A. Knowledge asset similarity and business relational capital gains: Evidence from European manufacturing firms. Knowl. Manag. Res. Pract. 2014, 12, 246-260. [CrossRef]

56. Singh, R.M.; Gupta, M. Knowledge management in teams: Empirical integration and development of a scale. J. Knowl. Manag. 2014, 18, 777-794. [CrossRef]

57. Interval Revenue Service (Servicio de Rentas Internas del Ecuador-SRI). Special Taxpayer Database. 2017. Available online: http://www.sri.gob.ec/web/guest/catastros (accessed on 29 June 2018). 
58. Unique Registry of Taxpayers Law (Ley de Registro Único de Contribuyentes). Official Registry Supplement 398; National Congress of the Republic of Ecuador: Quito, EcuAdor, 2004.

59. Naranjo-Gil, D. Salvando las dificultades del uso de la encuesta en la investigación contable de gestión: Una aplicación empírica. Rev. Esp. Financ. Contab. 2006, 35, 361-385. [CrossRef]

60. Dillman, D.A. Mail and Internet Surveys; John Wiley and Sons Inc.: New York, NY, USA, 2000.

61. Gold, A.H.; Malhotra, A.; Segars, A.H. Knowledge management: An organizational capabilities perspective. J. Manag. Inf. Syst. 2001, 18, 185-216. [CrossRef]

62. Naranjo-Gil, D. The role of management control systems and top teams in implementing environmental sustainability policies. Sustainability 2016, 8, 359. [CrossRef]

63. Naranjo-Gil, D. The use of the balanced scorecard and the budget in the strategic management of public hospitals. Gac. Sanit. 2010, 24, 220-224.

64. Hulland, J. Use of Partial Least Squares (PLS) in strategic management research: A review of four recent studies. Strateg. Manag. J. 1999, 20, 195-204. [CrossRef]

65. Chin, W.W. The Partial Least Squares Approach to Structural Equation Modeling; Marcoulides, G.A., Ed.; Modern Methods for Business Research: Mahwah, NJ, USA; Lawrence Erlbaum Associates: Mahwah, NJ, USA, 1998; pp. 295-336.

(C) 2020 by the authors. Licensee MDPI, Basel, Switzerland. This article is an open access article distributed under the terms and conditions of the Creative Commons Attribution (CC BY) license (http://creativecommons.org/licenses/by/4.0/). 